\title{
Comparative physiological and transcriptomic analyses reveal ascorbate and glutathione coregulation of cadmium toxicity resistance in wheat genotypes
}

Tao Zhang ${ }^{1 \dagger}$, Jingui Xiao ${ }^{1 \dagger}$, Yongsheng Zhao ${ }^{1 \dagger}$, Yifan Zhang ${ }^{1 \dagger}$, Yaqi Jie ${ }^{1 \dagger}$, Dandan Shen ${ }^{2}$, Caipeng Yue ${ }^{2}$, Jinyong Huang ${ }^{2}$, Yingpeng Hua ${ }^{2^{*}}$ and Ting Zhou ${ }^{2^{*}}$

\begin{abstract}
Background: Cadmium (Cd) is a heavy metal with high toxicity that severely inhibits wheat growth and development. Cd easily accumulates in wheat kernels and enters the human food chain. Genetic variation in the resistance to $\mathrm{Cd}$ toxicity found in wheat genotypes emphasizes the complex response architecture. Understanding the Cd resistance mechanisms is crucial for combating $\mathrm{Cd}$ phytotoxicity and meeting the increasing daily food demand.

Results: Using two wheat genotypes (Cd resistant and sensitive genotypes T207 and S276, respectively) with differing root growth responses to $\mathrm{Cd}$, we conducted comparative physiological and transcriptomic analyses and exogenous application tests to evaluate $\mathrm{Cd}$ detoxification mechanisms. $\mathrm{S} 276$ accumulated more $\mathrm{H}_{2} \mathrm{O}_{2}, \mathrm{O}_{2}{ }^{-}$, and MDA than T207 under Cd toxicity. Catalase activity and levels of ascorbic acid (AsA) and glutathione (GSH) were greater, whereas superoxide dismutase (SOD) and peroxidase (POD) activities were lower in T207 than in S276. Transcriptomic analysis showed that the expression of RBOHA, RBOHC, and RBOHE was significantly increased under Cd toxicity, and twothirds (22 genes) of the differentially expressed RBOH genes had higher expression levels in S276 than inT207. Cd toxicity reshaped the transcriptional profiling of the genes involving the AsA-GSH cycle, and a larger proportion (74.25\%) of the corresponding differentially expressed genes showed higher expression in T207 than S276. The combined exogenous application of AsA and GSH alleviated Cd toxicity by scavenging excess ROS and coordinately promoting root length and branching, especially in S276.
\end{abstract}

Conclusions: The results indicated that the ROS homeostasis plays a key role in differential $\mathrm{Cd}$ resistance in wheat genotypes, and the AsA-GSH cycle fundamentally and vigorously influences wheat defense against Cd toxicity, providing insight into the physiological and transcriptional mechanisms underlying $\mathrm{Cd}$ detoxification.

Keywords: Wheat, Cd resistance, Genotypic diversity, ROS, AsA-GSH cycle

*Correspondence: yingpenghua@zzu.edu.cn; zhoutt@zzu.edu.cn 'Tao Zhang, Jingui Xiao, Yongsheng Zhao, Yifan Zhang and Yaqi Jie contributed equally to this work.

${ }^{2}$ School of Agricultural Sciences, Zhengzhou University,

Zhengzhou 450001, People's Republic of China

Full list of author information is available at the end of the article

\section{Background}

Cadmium (Cd) is a heavy metal that is harmful to animals, plants, and microorganisms. With progressing industrialization and urbanization, $\mathrm{Cd}$ pollution is becoming increasingly serious in arable land and irrigation water, where it is absorbed by plants. Cd is highly mobile in soil; thus, it is easily absorbed by plants, 
resulting in retarded plant growth. Further, Cd is highly mobile in plants and easily contaminates agricultural products via vascular transportation [1]. It subsequently enters the human body via the food chain, and excessive intake or inhalation of $\mathrm{Cd}$ can damage the human immune, urinary, bone, nervous, reproductive, and other systems [2]. In addition, $\mathrm{Cd}$ has strong carcinogenic, teratogenic, and mutagenic effects $[3,4]$, resulting in diseases, such as "Itai-Itai disease" [5]. Hence, Cd has been listed as one of the 12 hazardous substances worldwide with environmental and food safety significance by the United Nations Environment Program since 1984 [6].

$\mathrm{Cd}$ toxicity inhibits seed germination and root growth, reduces photosynthesis, blocks the xylem, induces stomatal closure, and causes water and nutrient imbalances in plants $[7,8]$. Besides, it stimulates the burst of reactive oxygen species (ROS), and the excessive ROS causes the loss of cellular membrane integrity and damages the molecular structure of DNA, proteins, and lipids $[1,9]$. As a main and direct site for $\mathrm{Cd}$ adsorption and perception, the root has evolved various strategies to cope with $\mathrm{Cd}$ toxicity. These include the firm fixation of $\mathrm{Cd}$ in the root cell wall, reduced $\mathrm{Cd}$ transport to the aboveground parts, the expulsion of $\mathrm{Cd}$ from the root into the soil, or transportation of $\mathrm{Cd}$ into non-metabolic organelle vacuoles $[10,11]$. Another important resistance mechanism relies on enhancing antioxidant defense. Two ways are used to reduce oxidative damage and help maintain redox homeostasis in plants [12]: 1) the enzymatic antioxidant scavenging system that includes superoxide dismutase (SOD), peroxidase (POD), catalase (CAT), ascorbate peroxidase (APX), glutathione-S-transferase (GST), monodehydroascorbate reductase (MDHAR), and glutathione reductase (GR); and 2) the non-enzymatic antioxidants system, including ascorbic acid (AsA), glutathione (GSH), and nicotinamide adenine dinucleotide phosphate (NADPH) [13]. Among these antioxidants, reduced compounds play key roles because peroxidases can react with $\mathrm{H}_{2} \mathrm{O}_{2}$ rapidly, and their reduced forms are quickly regenerated by specific reductases [14]. AsA and GSH have strong reducibility and are localized in almost all cellular compartments, including the mitochondria, chloroplasts, peroxisomes, nuclei, cytosol, endoplasmic reticulum, and vacuoles. GSH is also present in the apoplast [15]. The role and function of AsA or GSH in scavenging excess ROS produced by environmental stress have been extensively studied. Akram et al. [16] summarized the role of AsA in reducing cellular oxidative stress in detail, and these studies mentioned evaluated the effects of AsA application in several plants under various environmental abiotic stresses, including high and low temperatures $[17,18]$, salinity [19], and drought [20]. Exogenous GSH treatment of postharvest bell pepper alleviated injury due to chills by regulating the AsA-GSH cycle [21]. For heavy metal stresses, Chao et al. [22] reported that hydroponic AsA treatment reduces the production of malondialdehyde (MDA) and increases chlorophyll content, helping alleviate the effects of $\mathrm{Cd}$ poisoning in rice. In Arabidopsis, exogenous GSH treatment inhibits $\mathrm{Cd}$ translocation from roots to shoots, whereas endogenous GSH does not inhibit translocation [23]. Cucumber seeds treated with exogenous AsA, proline, and GSH in turn reduced Cd toxicity in seedlings [24]. In plants, APX and GSH do not act separately. AsA, which serves as a special electron donor for APX to reduce $\mathrm{H}_{2} \mathrm{O}_{2}$ and $\mathrm{O}_{2}{ }^{-}$content, is oxidized to dehydroascorbic acid (DHAA), and the oxidized form is non-enzymatically reduced by GSH, thus forming the AsA-GSH cycle [25]. However, there is not enough research done on the interaction effects of GSH and AsA to improve environmental stress resistance, especially heavy metals in plants. Whether the ROS burst that occurs when plants encounter environmental stress induces a decrease or increase in AsA and GSH synchronously or triggers an imbalance in the AsA-GSH cycle remains unknown. These questions need to be further studied.

Currently, studies on $\mathrm{Cd}$ accumulation and tolerance mechanisms have mainly focused on model plants, such as Arabidopsis and rice. Extending the scope to other food crops, such as wheat, is desired. Wheat (Triticum aestivum L.) is a predominant cereal crop and the main staple food for more than $50 \%$ of the world's population [26]. In some areas, wheat and its products are vital contributors to dietary $\mathrm{Cd}$ intake by people, especially in countries lacking water, where farmers use wastewater to irrigate wheat, and in areas with high soil Cd concentrations $[27,28]$. Cd is more toxic to wheat than other heavy metals, such as chromium [29]. Cd hinders wheat shoot growth, causes chlorosis and necrosis of leaves, decreases leaf number and leaf area, and decreases yield [30-32]. As the major perception and adsorption site of $\mathrm{Cd}$, the growth of root was also severely affected [30-32]. In this study, we selected two wheat genotypes differing in root growth under $\mathrm{Cd}$ toxicity. Using these genotypes, we aimed to investigate $\mathrm{r}$ ROS generation and the role of enzymatic and non-enzymatic antioxidant systems in countering oxidative stress generated due to Cd toxicity. These findings may provide new insight into improving wheat resistance through modulation of ROS homeostasis in Cd-contaminated areas.

\section{Results}

Growth performance of wheat seedlings under Cd toxicity Increasing the $\mathrm{Cd}$ concentration, from 0 to $100 \mu \mathrm{M}$, administered to the plants caused the shoot height, root length, and the biomasses of both shoots and roots to 

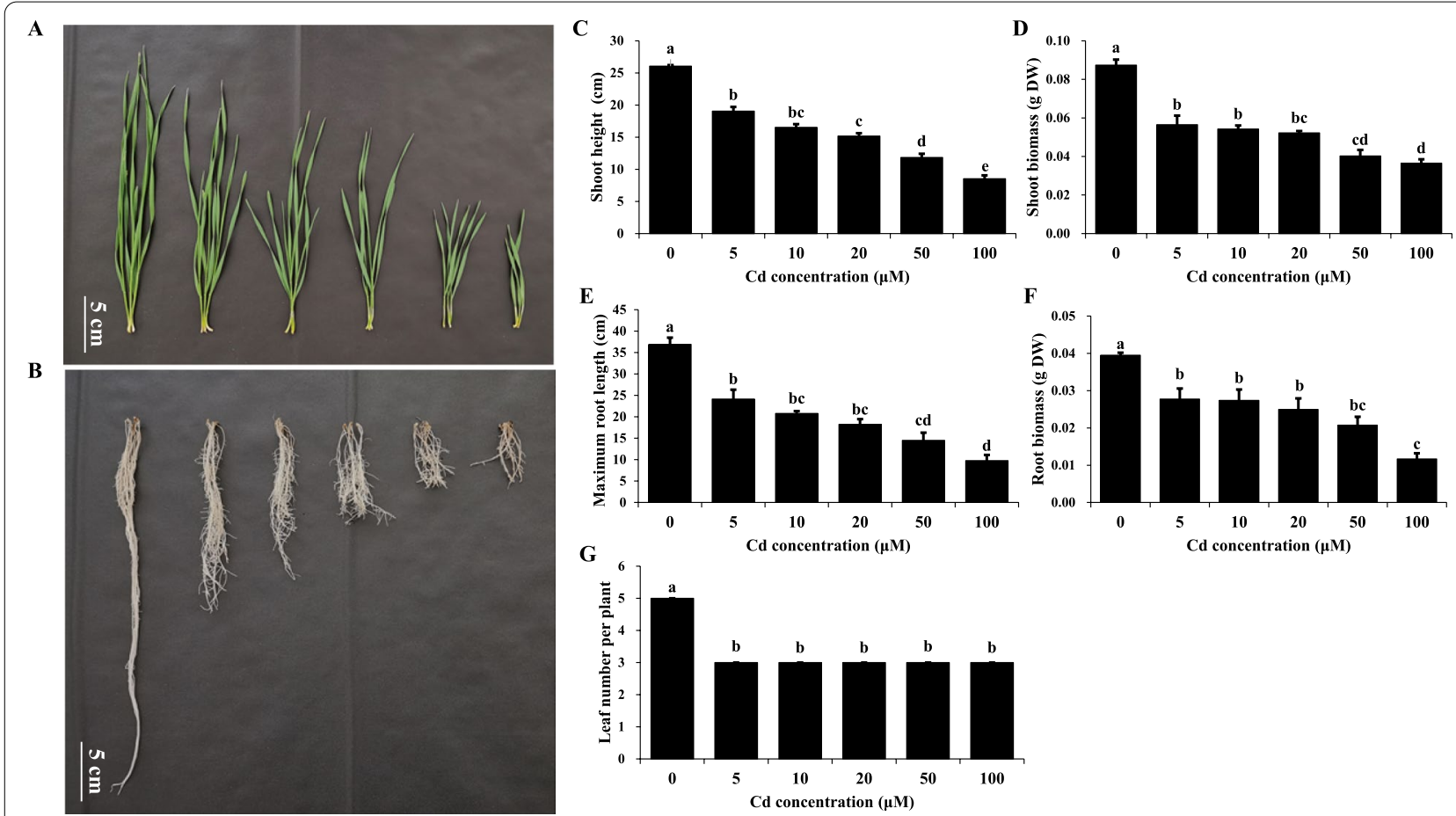

Fig. 1 Characterization of wheat growing under different $C d$ concentrations. A-B, Images of wheat shoots $(\mathbf{A})$ and roots $(\mathbf{B})$ growing under different $\mathrm{Cd}$ concentrations for $12 \mathrm{~d}$. From left to right, represent the phenotypes of plants grow in $0 \mu \mathrm{M}$ (control), $5 \mu \mathrm{M}, 10 \mu \mathrm{M}, 20 \mu \mathrm{M}, 50 \mu \mathrm{M}$, and $100 \mu \mathrm{M}$ $\mathrm{Cd}^{2+}$. C Shoot height of wheat growing under different $\mathrm{Cd}$ concentrations. D Shoot biomass of wheat growing under different $\mathrm{Cd}$ concentrations. E, Maximum root length of wheat growing under different $\mathrm{Cd}$ concentrations. F, Root biomass of wheat growing under different $\mathrm{Cd}$ concentrations. $\mathrm{G}$, Leaf number of wheat growing under different $\mathrm{Cd}$ concentrations. Results are means $\pm \mathrm{SE}$ of six biological replicates

decrease gradually compared with the control group (Fig. 1A-F). At all Cd concentrations administered inCd toxicity conditions for 12 days, the leaf number per plant was three, and the Cd-exposed wheat pants had two fewer leaves than those in Cd-free condition (Fig. 1G). As $5 \mu \mathrm{M} \mathrm{Cd}$ caused significant adverse effects on wheat, we selected $5 \mu \mathrm{M} \mathrm{Cd}$ for inducing $\mathrm{Cd}$ toxicity in this experiment.

Further, we investigated the physiological responses of different wheat genotypes to $\mathrm{Cd}$ toxicity. Cd toxicity decreased the shoot biomass up to 59.4 and $34.2 \%$, and reduced the shoot height to 78.8 and $62.7 \%$ in the Cdresistant genotype T207 and the $\mathrm{Cd}$-sensitive genotype S276, respectively, compared with the control (Fig. 2B and C). Similarly, Cd treatment decreased the root biomass of T207 and S276 up to 73.8 and 49.7\%, respectively, compared with the control (Fig. 2D). Cd toxicity also decreased the maximum root length of T207 and S276 up to 80.7 and $53.0 \%$, respectively (Fig. 2E). The shoot height and biomass and root length and biomass were all significantly higher in T207 than S276, under $\mathrm{Cd}$ treatment (Fig. 2B-E). These results suggested that the wheat root, highly sensitive to $\mathrm{Cd}$ toxicity, could be used as an assessment of Cd resistance, and the resistance index of T207 was higher than that of S276.

\section{Lipid peroxidation and ROS generation in responses to $\mathrm{Cd}$ toxicity}

After Cd stress, the concentration of MDA, an indicator of lipid peroxidation, was evaluated in the roots of the two wheat genotypes (Fig. 3A). MDA levels were significantly increased following $\mathrm{Cd}$ toxicity. Under conditions of $\mathrm{Cd}$ toxicity, the MDA level of S276 was $35 \%$ higher than that of T207. In addition, excessive $\mathrm{O}_{2}{ }^{-}$and $\mathrm{H}_{2} \mathrm{O}_{2}$ production in the root was found to be markedly increased in S276 after 3 days of Cd toxicity, especially the $\mathrm{H}_{2} \mathrm{O}_{2}$ concentration (Fig. $3 \mathrm{~B}$ and C). The $\mathrm{H}_{2} \mathrm{O}_{2}$ and $\mathrm{O}_{2}{ }^{-}$concentrations in the roots of $\mathrm{S} 276$ were 47 and $15 \%$ higher, respectively, than those in the roots of T207 under Cd toxicity. These data indicated that distinct oxidative responses may be an important contributor to the phenotypic differences between $\mathrm{Cd}$ resistant T207 and the Cd-sensitive S276 genotypes in conditions of $\mathrm{Cd}$ stress. 

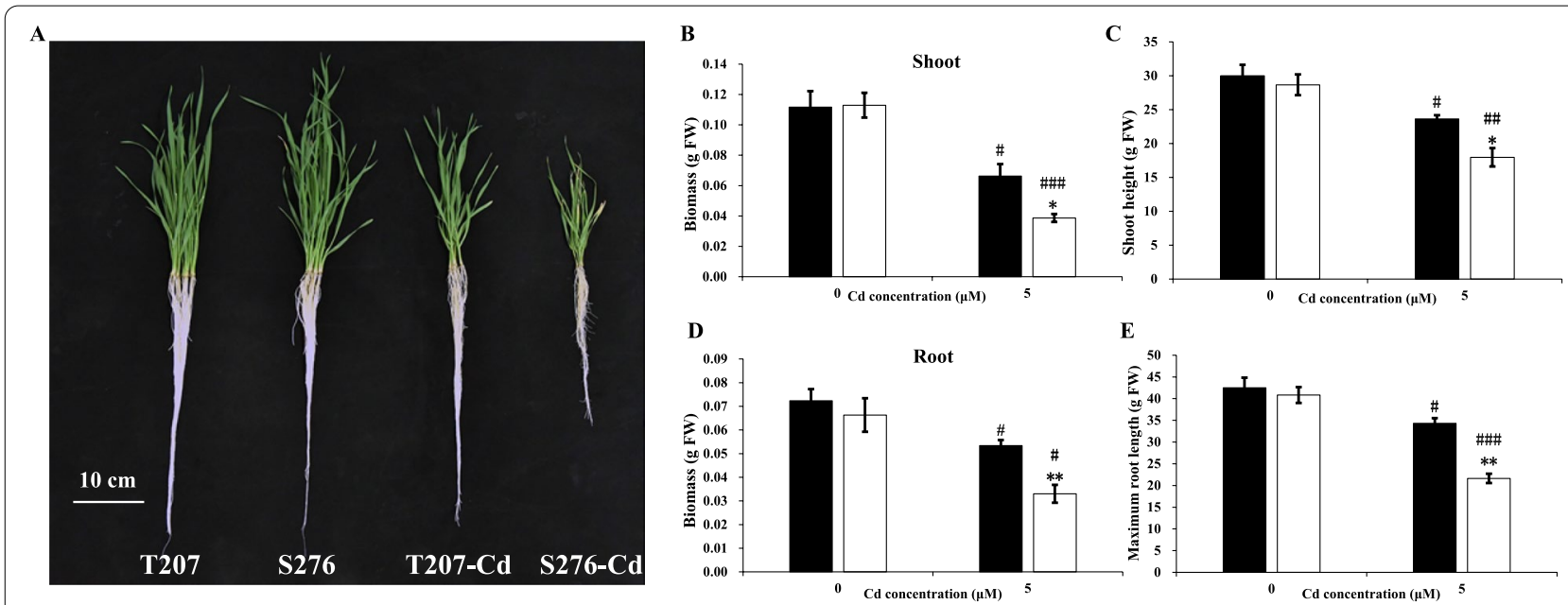

Fig. 2 Characterization of wheat genotypes T207 and S276 growing under normal or Cd treatment. A Images of T207 and S276 growing under normal or Cd treatment for $12 \mathrm{~d}$. B Shoot biomass of genotypes T207 and S276. C Shoot height of genotypes T207 and S276. D Root biomass of genotypes T207 and S276. E Maximum root length of genotypes T207 and S276. Results are means \pm SE of six biological replicates. The black column represents T207 and the white column represents S276. The symbols \# and * indicate statistically significant differences between treatments (normal and Cd conditions) (\#, $P<0.05, \# \#, P<0.01$ and \#\#\#,P<0.001) and between genotypes (T207 and S276) $\left(^{*}, P<0.05,{ }^{* *}, P<0.01\right.$ and $\left.{ }^{* * *}, P<0.001\right)$, respectively. FW, fresh weight

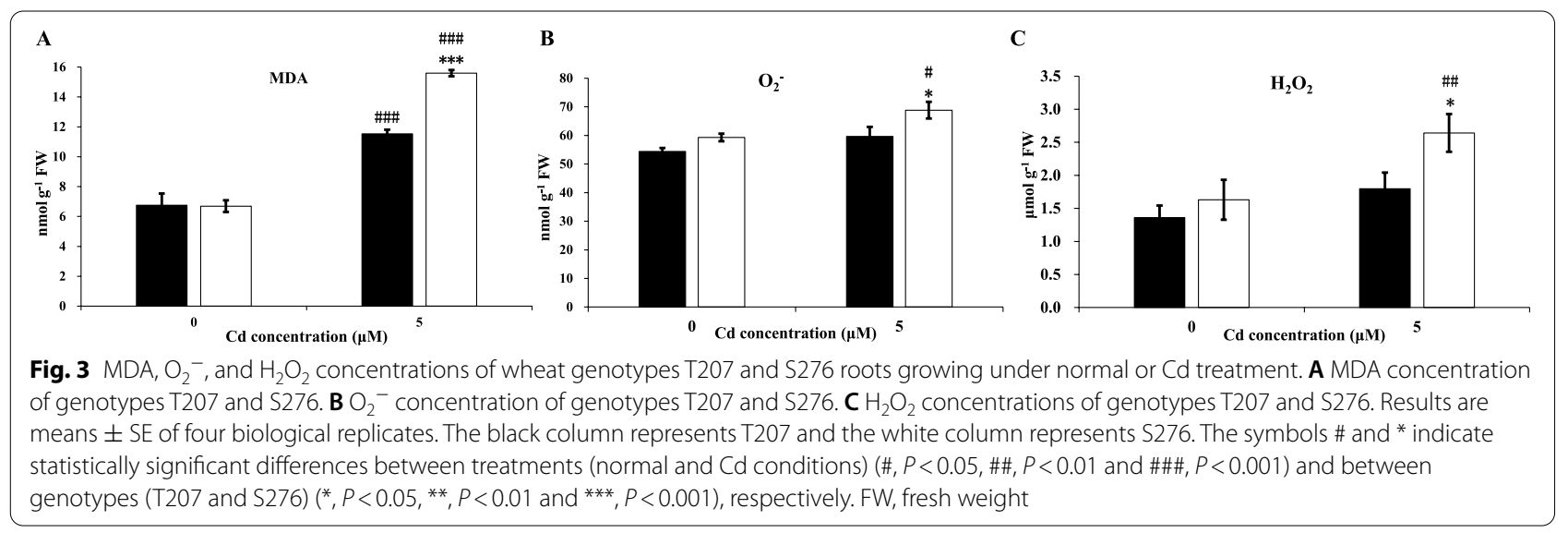

\section{Antioxidative enzyme activities and antioxidant levels under Cd stress}

Subsequently, we examined the activities of several key antioxidant enzymes and concentrations of antioxidants in T207 and S276 genotypes. The activities of SOD, POD, and CAT were significantly increased under Cd toxicity, whereas the opposite trend was observed for APX (Fig. 4). Under Cd toxicity, the CAT activity was significantly higher in T207 than in the S276 genotype (Fig. 4B); however, the SOD and POD activities were significantly higher in S276 than in T207 (Fig. 4A, C). The APX activity showed no significant differences between S276 and T207 (Fig. 4D). The concentrations of the non-enzymatic antioxidant AsA were more than three-fold higher than those of the control after Cd toxicity in T207 and S276, respectively (Fig. 5A); similarly, for the antioxidant GSH, the levels were 1380 and $764 \%$ higher than those in T207 and S276, respectively (Fig. 5B). These two antioxidants exhibited significantly higher concentrations in T207 than in S276 under Cd toxicity (Fig. 5).

\section{Digital gene expression profiling of ROS-related genes}

The significant increase in non-enzymatic antioxidants AsA and GSH in conditions of $\mathrm{Cd}$ toxicity indicated that the AsA-GSH cycle might contribute significantly to $\mathrm{Cd}$ resistance in wheat. The AsA-GSH cycle is an important part of the ROS regulation network that includes ROS-producing and ROS-detoxifying proteins 

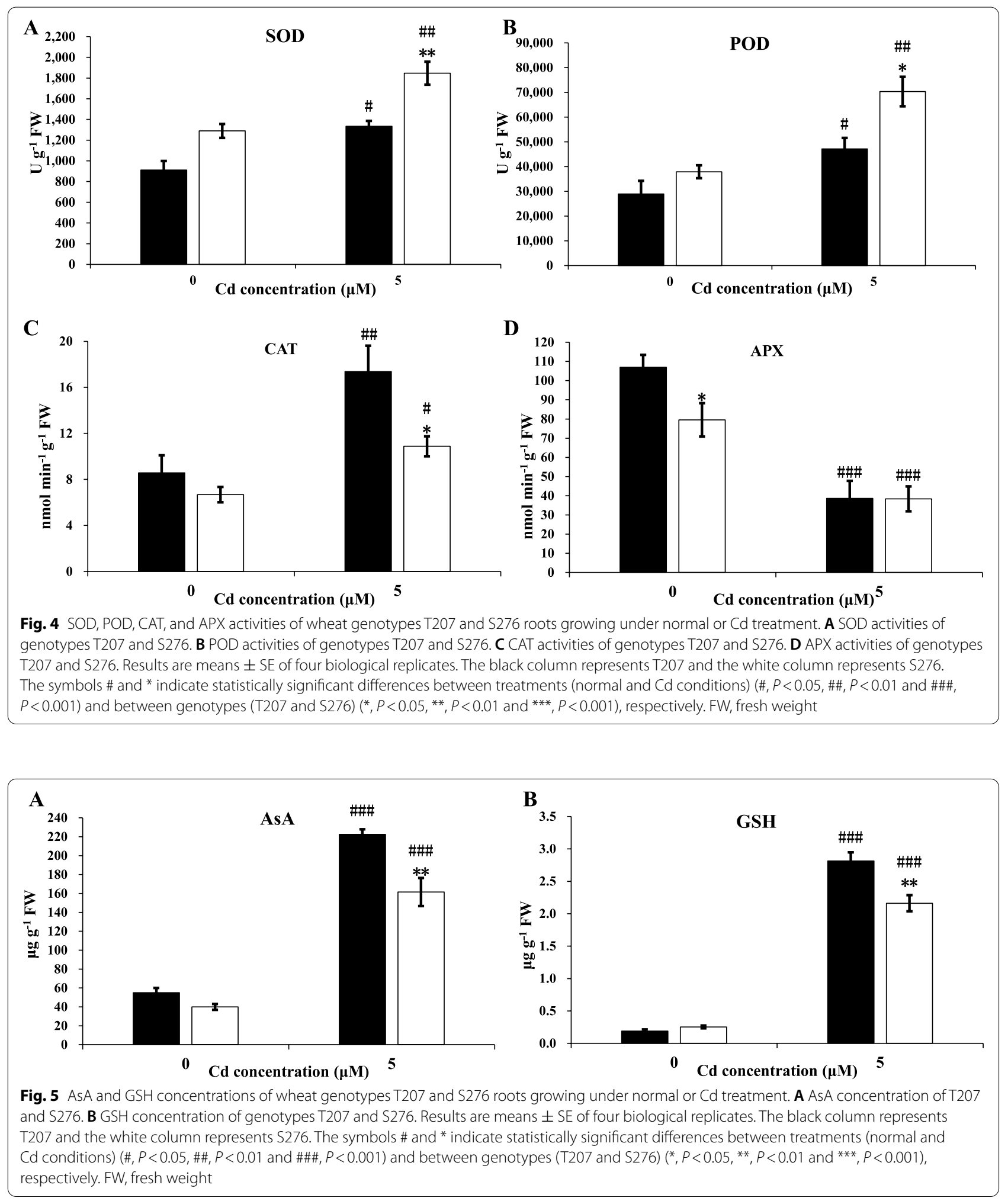

in the cell. Respiratory burst oxidase homologs, namely $R B O H s$ (RBOHA-J), are mainly responsible for ROS production in plants. The ROS-detoxifying genes mainly include genes encoding iron (Fe)-, manganese (Mn)-, and copper-zinc (CuZn)-SODs, CATs, APXs, glutathione peroxidases (GPXs), and peroxiredoxins 
A
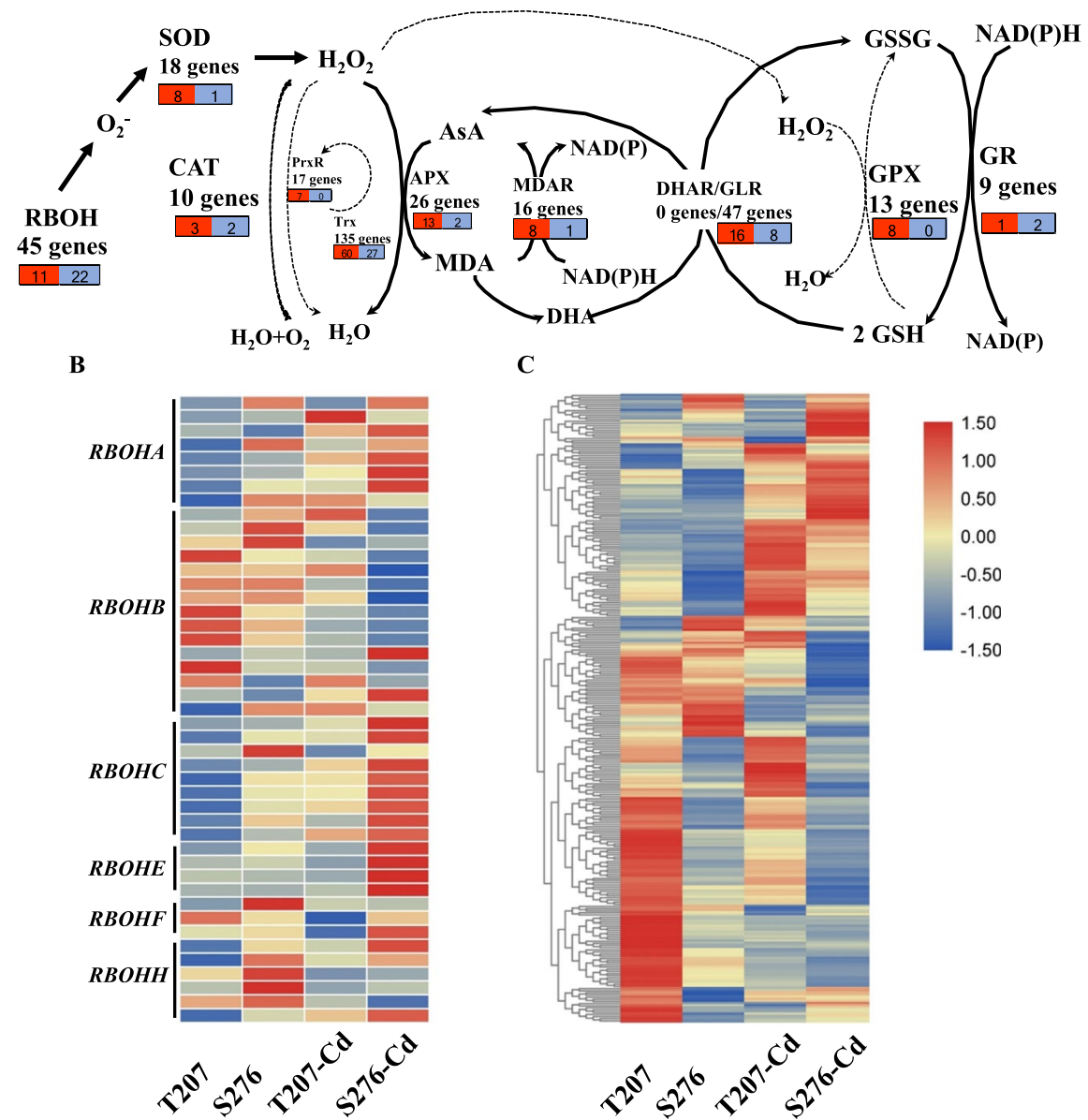

Fig. 6 The expression of genes involved in AsA-GSH cycle. A Genes involved in AsA-GSH cycle in wheat root. The red box indicates the numbers of genes that showed significantly higher expression in T207 than in S276 under Cd treatment. The blue box indicates the numbers of genes that showed significantly higher expression in S276 than in T207 under Cd treatment. B The heatmap of RBOH expression in wheat root. C The heatmap of genes involved in AsA-GSH cycle expression in wheat root

(PrxR). We investigated the expression of genes involved in the AsA-GSH cycle by high-throughput RNA-sequencing. A total of 336 genes were identified to be involved in the AsA-GSH cycle in allohexaploid wheat. In general, a higher percentage of genes had higher transcript levels in T207 than in S276 in the presence of $\mathrm{Cd}$ toxicity (Fig. 6A). The expression of $R B O H A, R B O H C$, and $R B O H E$ was significantly increased, whereas that of $R B O H B$ was significantly decreased by Cd toxicity (Fig. 6B). Except the $R B O H B$ subfamily, almost all other genes had higher transcript abundances in T207 than in S276. A total of $22 \mathrm{RBOH}$ homologs showed more abundant transcripts in S276 than in T207, whereas another 11 showed the opposite trend (Fig. 6A). Among the 18 SOD genes, the three $S O D-4 A$ s in wheat showed the highest expression levels and were significantly induced by $\mathrm{Cd}$ toxicity (Additional file 1).
Under Cd toxicity, eight genes exhibited significantly higher expression and one showed significantly lower expression in T207 than in S276. Among the 10 CAT genes, the expression of CAT2 and CATA showed the greatest level of induction in the presence of $\mathrm{Cd}$ toxicity. Further, the expression of three and two CAT gene s was significantly higher and lower in T207 than in S276 genotypes, respectively. Among the 26 APX genes in wheat, the expression of 13 and two were significantly higher and lower in T207 than in S276 genotypes under Cd toxicity, respectively. Among the $16 M D A R$ genes in wheat, eight and one showed significantly higher expression and lower expression in T207 than in S276 genotypes under $\mathrm{Cd}$ treatment, respectively. For the 13 GPX genes in wheat, eight were significantly highly expressed in T207 than in S276 under Cd treatment. Among the nine $G R$ genes in wheat, one exhibited significantly higher expression and two showed significantly lower expression 


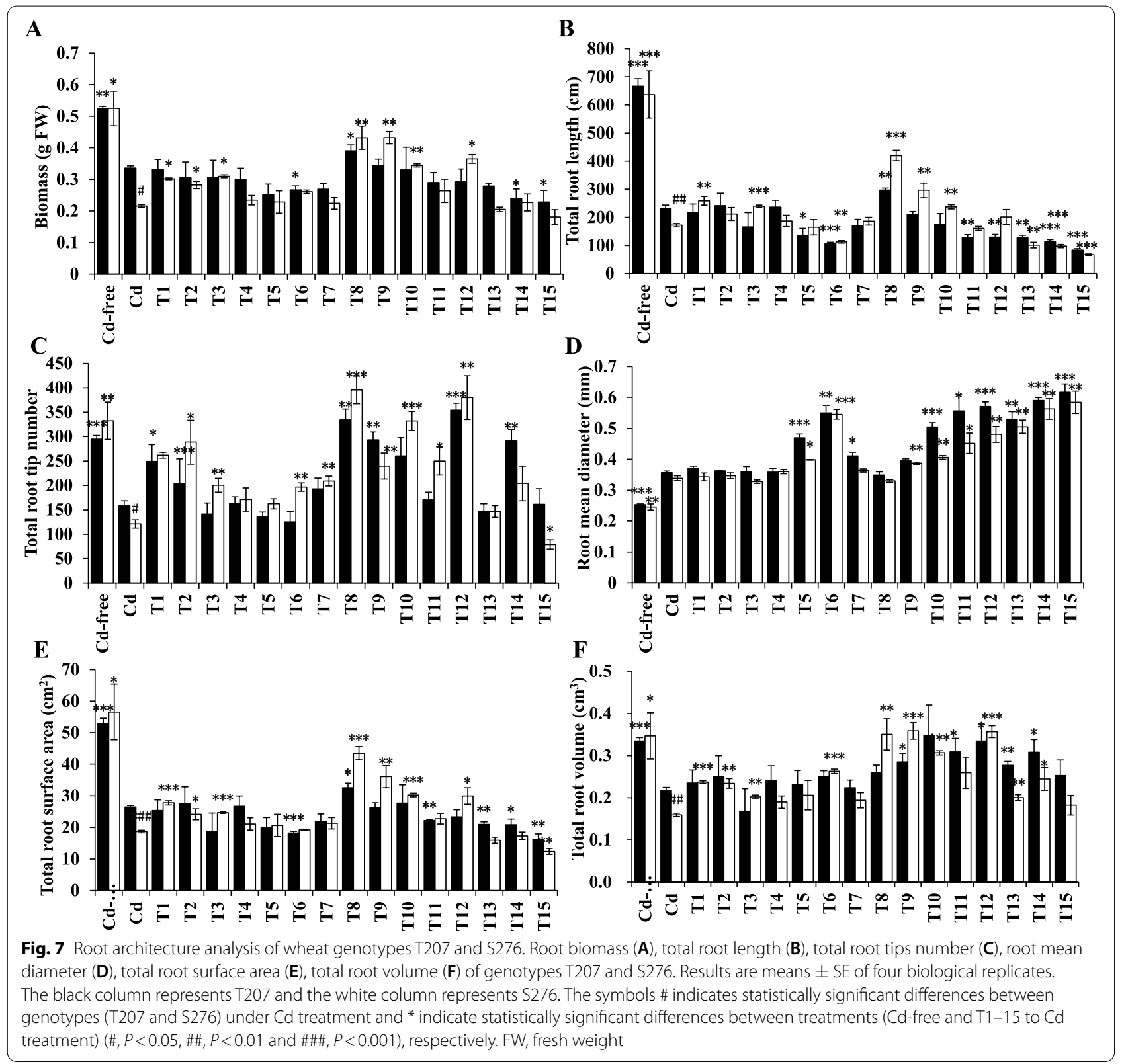

in T207 than in S276 under Cd stress. The other genes involved in the AsA-GSH cycle included $\operatorname{PrxR}$, Trx, and $G L R$. Most of these genes showed higher expressions in T207 than in S276 (Fig. 6A, C; Additional file 1). Besides, we also analyzed the genes encoding other ROS-producing enzymes such as oxalate oxidases; and proteins such as ferritin that store labile iron $\left(\mathrm{Fe}^{2+}\right)$ to protect cell from ROS damage. For the 23 genes encoding oxalate oxidases, six and eight were significantly higher and lower in T207 than in S276 under Cd toxicity, respectively. For the five Ferritin genes, no significant difference was observed between the T207 and S276 genotypes under Cd toxicity.
Root growth, lipid peroxidation, and ROS levels in response to exogenous AsA and GSH

Based on the results obtained, $\mathrm{Cd}$ stress increased the synthesis and accumulation of the antioxidants AsA and GSH. Therefore, we investigated the roles of these two antioxidants in reducing $\mathrm{Cd}$ toxicity-mediated oxidative damage. GSH application alone (T1-T3) significantly increased root biomass, total root length, root tip number, total root surface, and total root volume of S276 (Fig. 7A-C, E, F). AsA application alone (T4-T6) had relatively weaker effects on root system architecture (RSA), and it decreased the total root length and 
increased the root mean diameter significantly at a high concentration (T6: 0.8 mM AsA) (Fig. 7B, D), which usually indicates more severe $\mathrm{Cd}$ toxicity. The combined use of AsA and GSH significantly changed RSA. Application of $50 \mu \mathrm{M} \mathrm{GSH}+0.1 \mathrm{mM}$ AsA (T8) to Cd-stressed wheat significantly increased the root biomass, total root length, root tip number, total root surface, and total root volume (Fig. 8A-C, E, F). Additionally, the mean root diameter did not change (Fig. 7D). Therefore, T8 $(50 \mu \mathrm{M}$ GSH $+0.1 \mathrm{mM}$ AsA) was the best combination among the nine combinations evaluated. T9 $(100 \mu \mathrm{M}$ $\mathrm{GSH}+0.1 \mathrm{mM}$ AsA) treatment had similar effects to T8. The effect of improving wheat growth is mainly reflected in the genotype S276, which exhibits a greater vulnerability to Cd toxicity. Figure 8 shows the phenotype of Cd-free, $5 \mu \mathrm{M} \mathrm{Cd}, 5 \mu \mathrm{M} \mathrm{Cd}+\mathrm{T} 8(50 \mu \mathrm{M} \mathrm{GSH}+0.1 \mathrm{mM}$ AsA), and $5 \mu \mathrm{M} \mathrm{Cd}+\mathrm{T} 9(100 \mu \mathrm{M} \mathrm{GSH}+0.1 \mathrm{mM}$ AsA $)-$ treated wheat under $\mathrm{Cd}$ stress. Shoot and root growth were improved by the two treatments.

Further analysis after 3,3-N-diaminobenzidine tetrahydrochloride $(\mathrm{DAB})$, nitroblue tetrazolium chloride (NBT), and Evans blue staining were performed to identify the $\mathrm{H}_{2} \mathrm{O}_{2}$ and $\mathrm{O}_{2}^{-}$levels and cell viability, respectively. For the above staining methods, the roots were stained stronger after induction of $\mathrm{Cd}$ toxicity in both genotypes, especially in S276 (Fig. 9), which was consistent with the ROS and MDA levels (Fig. 3). The exogenous application of $50 \mu \mathrm{M}$ GSH $+0.1 \mathrm{mM}$ AsA and $100 \mu \mathrm{M}$ $\mathrm{GSH}+0.1 \mathrm{mM}$ AsA significantly decreased DAB, NBT, and Evans blue staining levels, especially in the S276 genotype (Fig. 9).

\section{Discussion}

Numerous studies have reported that Cd-contaminated soil adversely affects all aspects of plants. Root growth inhibition is a primary symptom of $\mathrm{Cd}$ toxicity and can be used to establish phenotypic and genotypic differences for $\mathrm{Cd}$ sensitivity or tolerance [33]. In this study, two wheat genotypes with differential root growth responses to $\mathrm{Cd}$ resistance were selected. Subsequently, a series of physiological and transcriptomic analyses were conducted to identify the mechanisms underlying the contrasting Cdresistance observed.

Physiological and biochemical studies indicated that $\mathrm{Cd}$ administration induced considerable ROS accumulation in the roots. Lower levels of ROS were produced in the Cd-resistant genotype T207 than in the Cd-sensitive genotype S276 (Figs. 3 and 9). Further, the MDA content and intensity of Evans blue staining, indicators of plasma membrane damage and cell death, were consistently higher in S276 than in T207 (Figs. 3 and 9), which might explain the $\mathrm{Cd}$ inhibition of root elongation in S276. RBOHs are the primary source of plasma membrane-associated ROS [34]. In the Arabidopsis genome, $10 \mathrm{RBOH}$ homologous genes (AtRBOH $A-J)$ have been annotated [35]. Different $R B O H$ copy numbers exist in other plant species, including six in barley [36] and 20 in Nicotiana tabacum [37]. Differentially expressed in different plant tissues, $\mathrm{RBOH}$-mediated ROS burst significantly affects plant physiological processes such as pollen tube growth and root hair cell expansion; and plant defenses against biotic and abiotic stresses, including heavy metals [38, 39]. identified The NADPH oxidase (RBOH) was identified to be a main source of Cd-induced $\mathrm{H}_{2} \mathrm{O}_{2}$ using diphenylene iodonium, an oxidase inhibitor [40]. However, the authors did not identify which $R B O H$ gene was the main contributor. In Arabidopsis, $C d$ administration induced the expression of $R B O H C$ and $R B O H D$ in leaves and $R B O H F$ in roots exposed to low $\mathrm{Cd}$ concentrations [41]. Using the Arabidopsis mutants rbohC, rbohD, and rbohF, Gupta et al. [38] found that compared with the wild type, the roots of these mutants grew poorly, whereas their leaves showed improved growth after 5 days of $\mathrm{Cd}$ toxicity. These studies showed that different $R B O H$ genes differentially regulate ROS metabolism under $\mathrm{Cd}$ toxicity conditions. Among the $45 R B O H$ genes in wheat, in general, the homologs of $R B O H A, R B O H C$, and $R B O H E$ were significantly induced by $\mathrm{Cd}$ toicity, and the expression levels of $22 \mathrm{RBOH}$ genes were higher in the S276 than T207 genotype, which was consistent with the higher $\mathrm{Cd}$-induced ROS content in S276 than T207 (Fig. 3B, C). Interestingly, RBOHB expression was significantly decreased by $\mathrm{Cd}$ toxicity, and its expression level was higher in T207 than in S276 (Fig. 6; Additional file 1). RBOHB is a root-specific protein in Arabidopsis [42] and functions in lateral root development in Phaseolus vulgaris [43]. Here, we found that root tip numbers were significantly decreased by administration of Cd toxicity, especially in the S276 genotype (Fig. $7 \mathrm{C}$ ), which may be related to the decreased expression of $R B O H B$. This phenomenon of the contrasting function of RBOHB compared with RBOHD and RBOHF has also been reported in Arabidopsis resistance against nematodes [42]. These results indicate that there is an intricate and finely tuned transcriptional regulation mechanism that restricts ROS production under $\mathrm{Cd}$ stress in wheat.

To minimize the ROS-induced oxidative damage, plants have evolved a sophisticated defense antioxidative system consisting of enzymatic and non-enzymatic components. Among the antioxidative enzymes, SOD and POD are the first line of defense against ROS. SOD catalyzes the dismutation of $\mathrm{O}_{2}^{-}$to $\mathrm{H}_{2} \mathrm{O}_{2}$ and molecular oxygen [12], whereas CAT and APX subsequently convert $\mathrm{H}_{2} \mathrm{O}_{2}$ to $\mathrm{H}_{2} \mathrm{O}$ [44]. A previous study showed that $\mathrm{Cd}$ is a metal without redox-active properties, which therefore 


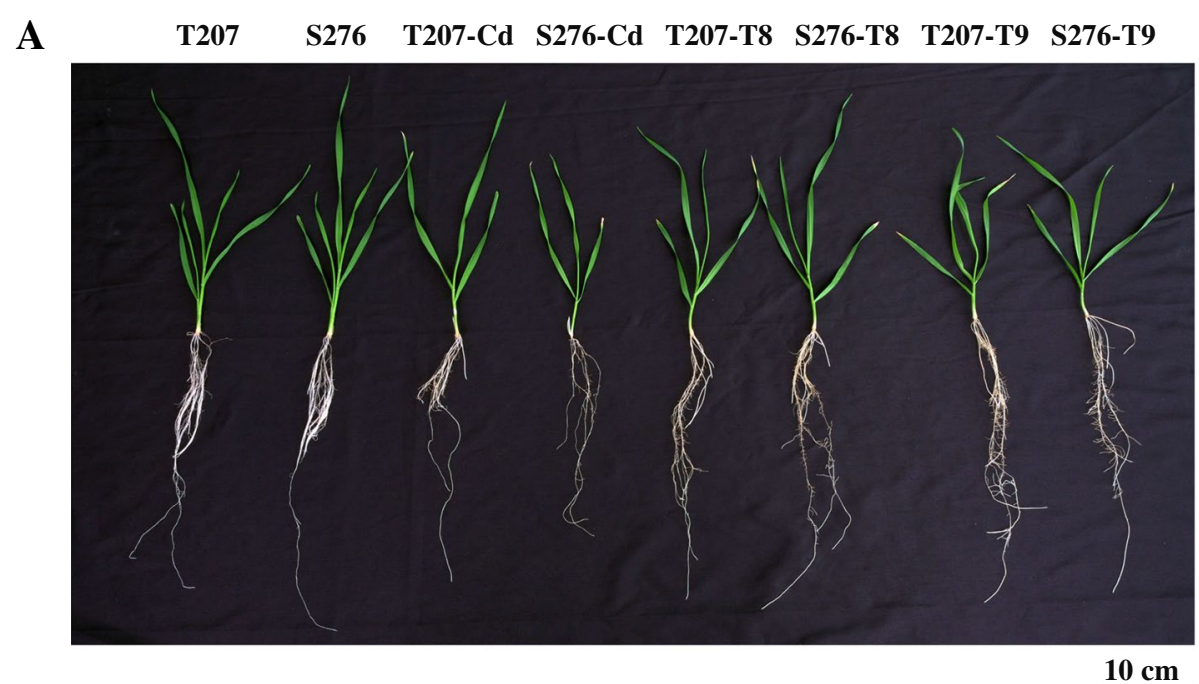

$\mathbf{B}$
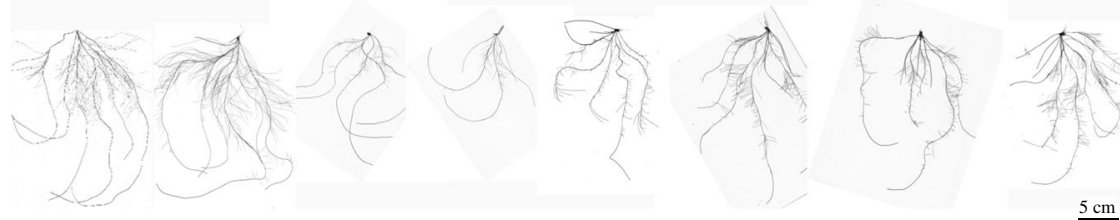

Fig. 8 The phenotypes of wheat genotypes T207 and S276 in response to exogenous AsA and GSH. A Whole plant phenotypes. B Root phenotypes. Cd: $5 \mu \mathrm{M} \mathrm{Cd}^{2+}, \mathrm{T} 8: 50 \mu \mathrm{M} \mathrm{GSH}+0.1 \mathrm{mM}$ AsA + $5 \mu \mathrm{MCd}^{2+}, \mathrm{T} 9: 100 \mu \mathrm{M} \mathrm{GSH}+0.1 \mathrm{mM} \mathrm{AsA}+5 \mu \mathrm{M} \mathrm{Cd}^{2+}$

did not participate directly in Fenton-type reactions-the source of ROS [45]. Therefore, Cd may cause the indirect accumulation of ROS by inhibiting antioxidant enzymes. However, a few studies have shown that variations in antioxidative enzyme activity under oxidative stress can be contradictory: increase, decrease, or no change can be observed [46, 47]; this is attributable to analysis in different plant species, plant tissues, or durations and concentrations of metal exposure. In this study, except for APX, activities of SOD, POD, and CAT were significantly induced by $\mathrm{Cd}$ (Fig. 4). This may be due to increased ROS production. Between the two genotypes, SOD and POD activities were significantly higher, whereas the CAT activity was significantly lower in the Cd-sensitive S276 than in the Cd-resistant T207 genotype. The basal levels of these enzymes showed similar trends (Fig. 4). These results were similar to those for different wheat genotypes in response to aluminum (Al) toxicity [48]. This suggests common mechanisms underlying wheat resistance to $\mathrm{Cd}$ and $\mathrm{Al}$ stress. Among the $A P X$ genes in Arabidopsis, cytosolic APX1 is a central component of the ROS gene network [49]. In this study, APX1 in wheat was significantly upregulated by $\mathrm{Cd}$ toxicity. However, the APX activity was significantly decreased, which is consistent with the response of wheat to copper toxicity [50], suggesting post-transcriptional regulation of the
APX activity in wheat. The AsA-GSH cycle - an important pathway to control $\mathrm{H}_{2} \mathrm{O}_{2}$ levels in cells - is present in all cell compartments. AsA and GSH react directly with $\mathrm{H}_{2} \mathrm{O}_{2}$ to eliminate its toxicity, and the regeneration of AsA requires GSH as a reductant [44]. In this study, AsA and GSH concentrations were increased greatly on exposure to $\mathrm{Cd}$ (Fig. 5). Similar results have been reported in Arabidopsis [38]. AsA and GSH concentrations were significantly higher in T207 than in S276 in the presence of $\mathrm{Cd}$ toxicity (Fig. 5), which also disturbed the expression of genes involved in the AsA-GSH cycle. A greater number of upregulated genes were identified in the AsA-GSH cycle in T207 than in S276 (Figs. 4, 5 and 6). These observations indicated that the AsA-GSH cycle in T207 was more efficient than that in S276 under $\mathrm{Cd}$ stress. With the development of molecular biology and genetic engineering (including metabolomics, epigenomics, CRISPR-Cas9, and high-throughput sequencing technologies), the identification of target genes that may help improve crop abiotic stress tolerance has been possible. Zafar et al. [51] have proposed that targeting ROS-related genes can achieve abiotic stress tolerance; for example, plants overexpressing melatonin (an antioxidative molecule that helps plants scavenge ROS) biosynthesis genes were found to be tolerant to different abiotic stresses. As a hexaploid crop, wheat contains 


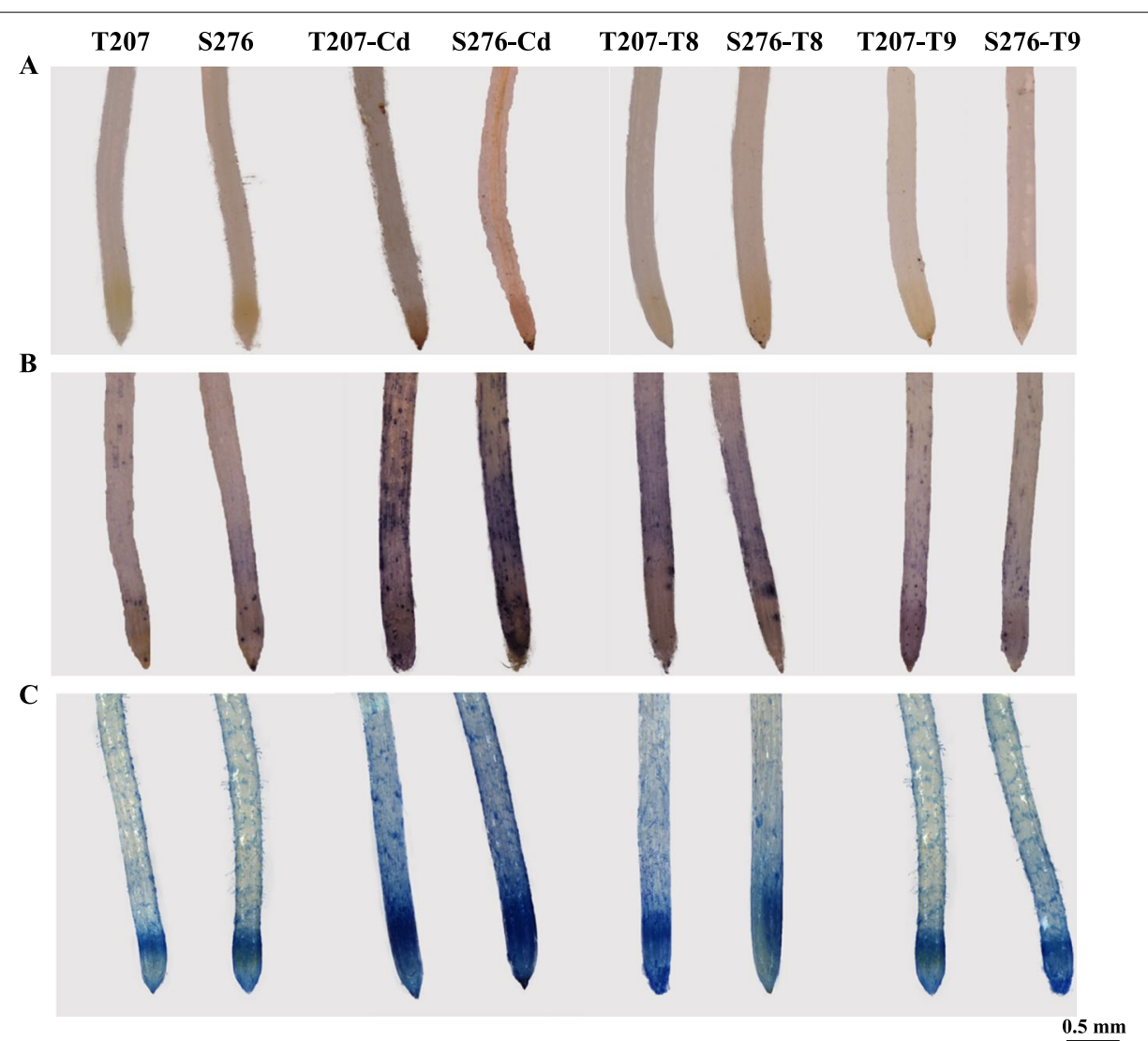

Fig. 9 Histochemical detection of $\mathrm{H}_{2} \mathrm{O}_{2}, \mathrm{O}_{2}^{-}$, and cell death of wheat genotypes T207 and $\mathrm{S} 276$ in response to exogenous AsA and GSH. A DAB staining of roots. B NBT staining of roots. C Evan's blue staining of roots. Cd: $5 \mu \mathrm{M} \mathrm{Cd}{ }^{2+}$, T8: $50 \mu \mathrm{M} \mathrm{GSH}+0.1 \mathrm{mM} \mathrm{AsA}+5 \mu \mathrm{M} C \mathrm{C}^{2+}, \mathrm{T} 9: 100 \mu \mathrm{M}$ $\mathrm{GSH}+0.1 \mathrm{mM} \mathrm{AsA}+5 \mu \mathrm{MCC^{2+ }}$

a large number of repetitive sequences and homologous chromosome segments, and hence multi- copies gene familiesin its genome. Using RNA-seq and comparisons between $\mathrm{Cd}$ toxicity tolerant and sensitive genotypes, we identified two APX1 copies (TraesCS4A02G106300 and TraesCS4D02G198500) that showed high expression levels, were strongly induced by $\mathrm{Cd}$ toxicity, and had significantly higher abundance in the $\mathrm{Cd}$ toxicity tolerant genotype than in the sensitive genotype (Additional file 1). These two genes may be promising gene modification targets that may help promote wheat $\mathrm{Cd}$ tolerance through maintaining redox balance in cells.

Both exogenous AsA and GSH can increase cell division activity and influence cell differentiation in the root apical meristem of Arabidopsis [52, 53]. However, their application does not result in the same effects on the RSA. AsA treatment promotes root length [52], whereas GSH promotes both the number and length of lateral roots [54]. Recent studies have demonstrated that the exogenous application of AsA or GSH can alleviate heavy metal stress. For example, Jung et al. found that exogenous AsA [55] or GSH [56] application alleviated arsenic toxicity in rice seedlings. Alamri et al. found that AsA and GSH independently alleviated arsenate toxicity in brinjal [57]. The role of AsA and GSH in alleviating Cd toxicity in wheat remains unclear. Cd significantly hinders plant root growth, reduces root length, increases root diameter [58], and inhibits root branching [59]. In this study, under $\mathrm{Cd}$ toxicity, exogenous administration GSH increased total root numbers, increasing the total root surface, total root volume, and root biomass. Exogenous ASA increased root mean diameter, decreased root length and diameter, and had no significant effect on the root surface, total root volume, and root biomass (Fig. 7). A previous study showed that spraying ASA alone alleviated $\mathrm{Cd}$-induced oxidative stress in rapeseed plants, whereas the aboveground biomass alone was significantly affected [60]. The result is similar to that from our study showing that the effect of AsA on the root biomass was slight (Fig. 7A), and high ASA resulted in shorter and thicker roots (Fig. 7B, D). Although AsA application alone did not improve the architecture of Cd-treated roots, the combined application of AsA and GSH significantly relieved the adverse growth of roots induced by 
$\mathrm{Cd}$, with significantly better results obtained than with GSH addition alone (Fig. 7). The combined application of AsA and GSH to Cd-stressed wheat seedlings increased root biomass, total root length, and total root tip numbers, and decreased the levels of MDA, $\mathrm{O}_{2}{ }^{-}$, and $\mathrm{H}_{2} \mathrm{O}_{2}$ compared to those under $\mathrm{Cd}$ toxicity (Figs. 7 and 9). Our results showed that $\mathrm{Cd}$-induced root growth impairment in wheat was correlated with the AsA and GSH levels. Plants may increase the activity of the AsA-GSH cycle to overcome Cd toxicity (Fig. 4). AsA and GSH contribute significantly to ROS scavenging and redox regulation under heavy metal stress [22, 61, 62] have been extensively studied. Their combined effects were studied here for the first time, and a $0.1 \mathrm{mM} \mathrm{AsA}+50 \mu \mathrm{M}$ GSH was found to alleviate $\mathrm{Cd}$ toxicity most significantly. Integrating the above theoretical analyses and experimental results, the combination application of exogenous AsA and GSH to Cd-exposed wheat, enhanced the metabolic intensity of the AsA-GSH cycle to scavenge excess ROS, and fine-tuned the root growth synergistically, alleviating Cd toxicity. This study highlighted the pivotal role of ROS homeostasis in determining Cd resistance in wheat genotypes through integrated physiological and transcriptional analyses. In the near future, the core genes regulating ROS production and scavenging should be identified in allohexaploid wheat, and characterization of the corresponding favorable alleles in the Cd-resistant wheat genotypes may provide elite gene resources for the genetic improvement of wheat $\mathrm{Cd}$ resistance.

\section{Conclusions}

To understanding the $\mathrm{Cd}$ resistance mechanisms in wheat, two wheat genotypes, the Cd-resistant T207 and the Cd-sensitive S276 were selected and the physiological and transcriptomic analysis were conducted.The results showed that the differential production of ROS by $\mathrm{Cd}$ had a key role in wheat $\mathrm{Cd}$ resistance. The $\mathrm{Cd}$ resistant genotypeT207 showed a better root architecture system, lower $\mathrm{O}_{2}{ }^{-}, \mathrm{H}_{2} \mathrm{O}_{2}$, and MDA concentrations, higher CAT activity, and more abundant AsA and GSH levels than the Cd-sensitive genotype S276 under Cd toxicity. Root transcriptomic profiling for T207 and S276 indicated that Cd administration-induced the transcriptional rearrangement of root genes involved in the ROS burst and the AsA-GSH cycle. Overall, the $R B O H$ homologs were more highly expressed in S276 than in T207 and a more active ROS-scavenging AsA-GSH cycle was identified in T207 than in S276. Our results also demonstrate that exogenous application of AsA and GSH alleviates Cd toxicity in wheat plants by scavenging excess ROS and regulating root growth synergistically, especially in the $\mathrm{Cd}$-sensitive genotype. The combination of $0.1 \mathrm{mM}$ AsA with $50 \mu \mathrm{M}$ GSH showed significant detoxification effects.
The results reported here provide valuable insight into the critical role of the ROS-mediated differential Cd sensitivity and the AsA-GSH cycle-mediated Cd resistance in wheat. . Two APX1 copies (TraesCS4A02G106300 and TraesCS4D02G198500) were identified as key players in the $\mathrm{Cd}$ toxicity. However, no further functional verification of these two genes was performed. Further genetic analysis of the elite genes is required to understand the Cd-detoxifying mechanisms and develop safer food in Cd-contaminated soils.

\section{Methods}

\section{Plant material}

In this study, wheat seeds were provided by the Wheat Research Institute, Henan Academy of Agricultural Sciences. Among the 126 wheat genotypes, we selected accession number 207 as a Cd toxicity-resistant genotype, and accession number 276 as a Cd toxicity-sensitive genotype. We named them T207 and S276, respectively, in this study.

\section{Plant growth}

Hydroponic culture was used for seed germination and seedling growth. Plump wheat seeds were surface-sterilized using $0.5 \%(\mathrm{w} / \mathrm{v}) \mathrm{NaClO}$ for $10 \mathrm{~min}$ and subsequently rinsed completely with pure water. After being allowed to germinate on gauze for 5 days, uniform seedlings were transplanted into black plastic containers with Hoagland and Arnon [63] solution. The full-strength solution contained $5.0 \mathrm{mM} \mathrm{KNO}, 5.0 \mathrm{mM} \mathrm{Ca}\left(\mathrm{NO}_{3}\right)_{2}$, $2.0 \mathrm{mM} \mathrm{MgSO} \cdot 7 \mathrm{H}_{2} \mathrm{O}, 1.0 \mathrm{mM} \mathrm{KH}_{2} \mathrm{PO}_{4}, 50 \mu \mathrm{M}$ EDTA$\mathrm{Fe}, \quad 46 \mu \mathrm{M} \quad \mathrm{H}_{3} \mathrm{BO}_{3}, \quad 9.0 \mu \mathrm{M} \quad \mathrm{MnCl}_{2} \cdot 4 \mathrm{H}_{2} \mathrm{O}, \quad 0.80 \mu \mathrm{M}$ $\mathrm{ZnSO}_{4} \cdot 7 \mathrm{H}_{2} \mathrm{O}, 0.37 \mu \mathrm{M} \mathrm{Na} \mathrm{NoO}_{4} \cdot 2 \mathrm{H}_{2} \mathrm{O}$, and $0.30 \mu \mathrm{M}$ $\mathrm{CuSO}_{4} \cdot 5 \mathrm{H}_{2} \mathrm{O}$. The nutrient solution was replaced every 3 days. The wheat seedlings were grown in one-quarterstrength, one-half-strength, and eventually full-strength solutions. The plants were grown in a climate chamber using a temperature setting of $24 / 22^{\circ} \mathrm{C}$ (day/night), a photoperiod of $14 / 10 \mathrm{~h}$ (day/night), and light intensity of $300-320 \mu \mathrm{mol} \mathrm{m}^{-2} \mathrm{~s}^{-1}$.

\section{Experimental design $\mathrm{Cd}$ concentration gradient treatments and selection of tolerant and sensitive cultivars}

Uniform wheat seedlings after 5 -d seed germination were treated with $\mathrm{CdCl}_{2}$ at six concentrations: $0,5,10,20,50$, and $100 \mu \mathrm{M}$ for 12 days. Shoot height $(\mathrm{cm})$ and biomass $(\mathrm{g})$, root length $(\mathrm{cm})$ and biomass $(\mathrm{g})$, and leaf number were recorded.

A total of 126 wheat genotypes germinated and grew in pure water for 5 days, and the seedlings were transferred to a nutrient solution containing $5 \mu \mathrm{M} \mathrm{Cd}^{2+}$. Root biomass and length were measured after 12 days. The genotype with extremely high and low root biomass and 
length was selected as Cd-tolerant and sensitive genotypes, respectively.

\section{Physiological and transcriptional responses to $\mathrm{Cd}^{2+}$ in both cultivars}

Uniform wheat seedlings after 5-d seed germination were grown in normal solution for 7 days, and were divided into two experimental groups based on $\mathrm{Cd}$-free (normal culture) and $\mathrm{Cd}\left(5 \mu \mathrm{M} \mathrm{Cd}^{2+}\right)$ treatments. After 3 days, the samples were harvested to evaluate ROS concentrations, antioxidative enzyme activity, antioxidant concentrations, and for transcriptome sequencing.

\section{Addition of exogenous antioxidants}

Uniform wheat seedlings after 5-d seed germination were grown in normal solution for 7 days and were subsequently treated with differential exogenous antioxidant concentrations. The treatment plan is outlined in Table 1. After 7 days, the RSA parameters were analyzed and root microscopy was performed.

\section{Evaluation of ROS, MDA, antioxidant concentrations, and antioxidative enzyme activities}

Root samples were homogenized in $50 \mathrm{mM}$ PBS buffer $(\mathrm{pH}=7.8)$. The homogenates were centrifuged at $8000 \times g$ for $15 \mathrm{~min}$ at $4{ }^{\circ} \mathrm{C}$. The supernatant was treated with $10 \mathrm{mM}$ hydroxylamine hydrochloride and bathed in warm water at $25^{\circ} \mathrm{C}$ for $1 \mathrm{~h}$. Next, $17 \mathrm{mM}$ p-aminobenzene sulfonic acid and $7 \mathrm{mM} \alpha$-naphthylamin were added to the reaction solution and placed in warm water at $25^{\circ} \mathrm{C}$ for $20 \mathrm{~min}$. The $\mathrm{O}_{2}{ }^{-}$concentration was analyzed spectrophotometrically at $530 \mathrm{~nm}$. For $\mathrm{H}_{2} \mathrm{O}_{2}$ level analysis, root samples were homogenized using precooled acetone and centrifuged at $10000 \times g$ for $10 \mathrm{~min}$ at $4{ }^{\circ} \mathrm{C}$. The supernatant was reacted with $20 \%$ titanium chloride. After mixing well, $40 \mu \mathrm{l}$ of concentrated ammonia was added for sample precipitation. The precipitate was washed three times with acetone and then dissolved in $1 \mathrm{M} \mathrm{H}_{2} \mathrm{SO}_{4}$. The absorbance at $410 \mathrm{~nm}$ was measured.

The level of lipid peroxidation is usually indicated by the MDA content [64]. Root samples were homogenized in $5 \%$ trichloroacetic acid. The homogenates were centrifuged at $3000 \times g$ for $10 \mathrm{~min}$ at $4{ }^{\circ} \mathrm{C}$. The supernatant was reacted with $0.67 \%$ thiobarbituric acid (TBA) and placed in boiling water for $30 \mathrm{~min}$ to form a red product. The homogenates were centrifuged at $10000 \times g$ for $10 \mathrm{~min}$ at room temperature. The supernatant was assayed spectrophotometrically at $450 \mathrm{~nm}, 532 \mathrm{~nm}$, and $600 \mathrm{~nm}$. The MDA concentration was calculated as follows: $\mathrm{C} /$ $\mu \mathrm{mol} / \mathrm{L}=6.45 *\left(\mathrm{~A}_{532}-\mathrm{A}_{600}\right)-0.56 * \mathrm{~A}_{450}$ [64].

For antioxidative enzyme activity analysis, root samples were homogenized in 50-mM phosphate buffer (PBS, $\mathrm{pH}=7.0)$ containing $1 \mu \mathrm{M}$ EDTA. The homogenates were centrifuged at $14000 \times \mathrm{g}$ for $20 \mathrm{~min}$ at $4{ }^{\circ} \mathrm{C}$. Subsequently, the supernatant was used for the enzyme assays based on the method of Zafar et al. [65]. $\mathrm{O}_{2}{ }^{-}$reduces NBT to produce formazan. SOD has anti-oxidant activity against $\mathrm{O}_{2}{ }^{-}$; thus formazan content indicates SOD activity [66]. One unit (U) of SOD activity represents $50 \%$ inhibition of formazan production. POD catalyzes $\mathrm{H}_{2} \mathrm{O}_{2}$ and forms guaiacol via dehydrogenation. POD activity was monitored by the formation of guaiacol dehydrogenation at $470 \mathrm{~nm}$. CAT activity was monitored by analyzing the decomposition of $\mathrm{H}_{2} \mathrm{O}_{2}$ at $240 \mathrm{~nm}$. APX activity was determined by observing the decrease in AsAabsorbance at $290 \mathrm{~nm}$ over $2 \mathrm{~min}$. SOD, POD, CAT, and APX activities were evaluated using the following assay kits: SOD1-Y, POD-1-Y, CAT-1-Y, and APX-1-W, respectively (Coming Medical Technology Co., Ltd., Suzhou, China).

For antioxidant assays, AsA was analyzed by reacting the supernatant with Fast Blue B salt and the reaction was assayed spectrophotometrically at $420 \mathrm{~nm}$. GSH was analyzed after reacting it with 5,5'-Dithiobis-2-nitrobenzoic acid and the reaction products were assayed spectrophotometrically at $412 \mathrm{~nm}$. AsA and GSH were evaluated using the following assay kit: ASA-1-W and GSH-1-W, respectively (Coming Medical Technology Co., Ltd., Suzhou, China).

\section{Microscopy analysis}

$\mathrm{H}_{2} \mathrm{O}_{2}$ was analyzed in root samples by immersion in $0.5 \%$ $(\mathrm{w} / \mathrm{v}) \mathrm{DAB}$, and the samples were incubated at room temperature until the root turned brown [35]. $\mathrm{O}_{2}{ }^{-}$was detected by reacting with $0.2 \%(\mathrm{w} / \mathrm{v}) \mathrm{NBT}$ at $37^{\circ} \mathrm{C}$ to produce a blue formazan precipitate in the root [67]. The loss of cell viability was analyzed using $0.25 \%$ (w/v) Evans blue solution-based staining for $5 \mathrm{~min}$ and the samples were washed three times with $100 \mu \mathrm{M} \mathrm{CaCl}_{2}$ solution

Table 1 Addition of exogenous antioxidants for different treatments

\begin{tabular}{|c|c|c|c|c|c|c|c|c|c|c|c|c|c|c|c|c|c|}
\hline Treatment & Cd-free & $C d$ & $T 1$ & $T 2$ & $T 3$ & $T 4$ & $T 5$ & $T 6$ & $T 7$ & $T 8$ & T9 & $T 10$ & $T 11$ & $T 12$ & $T 13$ & $T 14$ & $T 15$ \\
\hline$C d^{2+}(\mu \mathrm{M})$ & 0 & 5 & 5 & 5 & 5 & 5 & 5 & 5 & 5 & 5 & 5 & 5 & 5 & 5 & 5 & 5 & 5 \\
\hline $\mathrm{GSH}(\mu \mathrm{M}))$ & 0 & 0 & 20 & 50 & 100 & 0 & 0 & 0 & 20 & 50 & 100 & 20 & 50 & 100 & 20 & 50 & 100 \\
\hline $\mathrm{AsA}(\mathrm{mM})$ & 0 & 0 & 0 & 0 & 0 & 0.1 & 0.4 & 0.8 & 0.1 & 0.1 & 0.1 & 0.4 & 0.4 & 0.4 & 0.8 & 0.8 & 0.8 \\
\hline
\end{tabular}


( $\mathrm{pH}=5.6)$ [68]. A fluorescent microscope (LSM800, Carl Zeiss, Oberkochem, Germany) was used for observation.

\section{High-throughput RNA-sequencing and differential expression analysis}

Wheat roots were harvested from $\mathrm{Cd}$-free and $\mathrm{Cd}$-treated plants for transcriptomic analysis, using three biological replicates for analysis. Purified total RNA of the fresh wheat roots were sequenced using an Illumina Hiseq $\mathrm{X}$ Ten platform (Illumina Inc., San Diego, CA, USA). The cDNA libraries were prepared following Tru-Seq ${ }^{\mathrm{TM}}$ RNA sample preparation Kit from Illumina (Illumina Inc., San Diego, California, USA). A total of 12 RNA samples were analyzed, which generated $6.0 \mathrm{~Gb}$ of sequencing data with $150 \mathrm{bp}$ paired-end (PE) reads per sample. The raw paired end reads were trimmed and quality controlled by SeqPrep (https://github.com/jstjohn/SeqPrep) and Sickle (https://github.com/najoshi/sickle) with default parameters. Then, clean reads were separately aligned to reference genome with orientation mode using TopHat (http://tophat.cbcb.umd.edu/, version 2.0.0) Transcript abundances (FPKM values) were calculated from RNAseq data using the method described by Zhou et al. [69]. The differentially expressed genes (DEGs) were defined as those with a $p$ value and false discovery rate that were less than 0.05 .

\section{Determination of root system architecture}

WinRHIZO (Pro 2013a, Regent Instrument Inc.), a root analysis software, was used to measure the RSA parameters, including total root length, average root diameter, root tip number, root surface area, and total root volume.

\section{Statistical analysis}

A randomized block design was used in all trials. Using GraphPad Prism 5.01, the differences among Cd concentration gradient treatments were evaluated using the Tukey test. The significant differences between control and treatment groups (Cd-free and Cd stress) or between genotypes (T207 and S276) were evaluated with the Student's $t$-test. Differences were considered statistically significant at $p<0.05$.

\footnotetext{
Abbreviations

Cd: Cadmium; AsA: Ascorbic acid; GSH: Glutathione; ROS: Reactive oxygen species; SOD: Superoxide dismutase; POD: Peroxidase; CAT: Catalase; APX: Ascorbate peroxidase; GST: Glutathione-S-transferase; MDHAR: Monodehydroascorbate reductase; GR: Glutathione reductase; NADPH: Nicotinamide adenine dinucleotide phosphate; MDA: Malondialdehyde; DHAA: Dehydroascorbic acid; RBOH: Respiratory burst oxidase homolog; GPX: Glutathione peroxidase; PrxR: Peroxiredoxins; DPI: Diphenylene iodonium; RSA: Root system architecture; TBA: Thiobarbituric acid; PBS: Phosphate buffer; NBT: Nitroblue tetrazolium chloride; DAB: 3,3-N-diaminobenzidine tetrahydrochloride.
}

\section{Supplementary Information}

The online version contains supplementary material available at https://doi. org/10.1186/s12870-021-03225-w.

Additional file 1. The expression of genes involved in AsA-GSH cycle.

\section{Acknowledgements}

Not applicable.

\section{Authors' contributions}

Tao Zhang, Jingui Xiao, Yongsheng Zhao, Yifan Zhang, and Yaqi Jie conducted the experiments, analyzed the data, and drafted the manuscript. Dandan Shen edited the manuscript. Caipeng Yue provided conceptual advice. Jinyong Huang supervised the research work. Yingpeng Hua designed the study and supervised the research work. Ting Zhou conceived the idea, provided critical review, and edited the manuscript. The author(s) read and approved the final manuscript.

\section{Funding}

This work was financially supported by the National Natural Science Foundation of China (31801923 and U2004149), Major Collaborative Innovation Project of Zhengzhou city (Key Discipline Construction Project of Zhengzhou University) (xkzdjc201905), Youth Innovation Project of Key discipline of Zhengzhou University (XKZDQN202002), and Innovation Ecosystem Construction Science and Technology Special Project of National Supercomputing Zhengzhou Center (201400210600). The funder was not involved in the experimental design of the study, data collection, analysis and interpretation, and in writing the manuscript.

\section{Availability of data and materials}

The datasets generated and analyzed during the current study are available from the corresponding author on reasonable request.

\section{Declarations}

Ethics approval and consent to participate Not applicable.

\section{Consent for publication}

Not applicable.

\section{Competing interests}

The authors declare that the research was conducted in the absence of any commercial or financial relationships that could be construed as a potential conflict of interest.

\section{Author details}

'School of Life Sciences, Zhengzhou University, Zhengzhou 450001, People's Republic of China. ${ }^{2}$ School of Agricultural Sciences, Zhengzhou University, Zhengzhou 450001, People's Republic of China.

Received: 8 July 2021 Accepted: 21 September 2021

Published online: 08 October 2021

\section{References}

1. Rizwan M, Ali S, Adrees M, Rizvi H, Zia-ur-Rehman M, Hannan F, et al. Cadmium stress in rice: toxic effects, tolerance mechanisms, and management: a critical review. Environ Sci Pollut Res Int. 2016;23(18):17859-79.

2. Wu ZY, Naveed S, Zhang CH, Ge Y. Adequate supply of sulfur simultaneously enhances iron uptake and reduces cadmium accumulation in rice grown in hydroponic culture. Environ Pollut. 2020;262:114327.

3. Wang P, Chen H, Kopittke PM, Zhao FJ. Cadmium contamination in agricultural soils of China and the impact on food safety. Environ Pollut. 2019;249:1038-48.

4. Bernard A. Cadmium \& its adverse effects on human health. Indian J Med Res. 2008;128(4):557-64. 
5. Kasuya M, Teranishi H, Aoshima K, Katoh T, Horiguchi H, Morikawa Y, et al. Water pollution by cadmium and the onset of itai-itai disease. Wat Sci Tech. 1992;25:149-56.

6. Nordberg GF. Historical perspectives on cadmium toxicology. Toxicol Appl Pharmacol. 2009;238:192-200.

7. Haider FU, Cai LQ, Coulter JA, Cheema SA, Wu J, Zhang RZ, et al. Cadmium toxicity in plants: impacts and remediation strategies. Ecotox Environ Safe. 2021;211:111887.

8. Gallego SM, Pena LB, Barcia RA, Azpilicueta CE, Lannone MF, Rosales EP, et al. Unravelling cadmium toxicity and tolerance in plants: insight into regulatory mechanisms. Environ Exp Bot. 2012;83:33-46.

9. Cuypers A, Plusquin M, Remans T, Jozefczak M, Keunen E, Gielen H, et al. Cadmium stress: an oxidative challenge. Biometals. 2010;23(5):927-40.

10. Rizwan M, Ali S, Adrees M, Ibrahim M, Tsang DCW, Zia-Ur-Rehman M, et al. A critical review on effects, tolerance mechanisms and management of cadmium in vegetables. Chemosphere. 2017;182:90-105.

11. Shahid M, Dumat C, Khalid S, Niazi NK, Antunes PMC. Cadmium bioavailability, uptake, toxicity and detoxification in soil-plant system. Rev Environ Contam Toxicol. 2017;241:73-137.

12. Giannakoula A, Moustakas M, Syros T, Yupsanis T. Aluminum stress induces up-regulation of an efficient antioxidant system in the Altolerant maize line but not in the Al-sensitive line. Environ Exp Bot. 2010;67(3):487-94.

13. Gill SS, Tuteja N. Reactive oxygen species and antioxidant machinery in abiotic stress tolerance in crop plants. Plant Physiol Biochem. 2010;48(12):909-30.

14. Foyer $\mathrm{CH}$, Noctor $\mathrm{G}$. Ascorbate and glutathione: the heart of the redox hub. Plant Physiol. 2011;155(1):2-18.

15. Koffler BE, Bloem E, Zellnig G, Zechmann B. High resolution imaging of subcellular glutathione concentrations by quantitative immunoelectron microscopy in different leaf areas of Arabidopsis. Micron. 2013:45:119-28.

16. Akram NA, Shafiq F, Ashraf M. Ascorbic acid-a potential oxidant scavenger and its role in plant development and abiotic stress tolerance. Front Plant Sci. 2017;8:613

17. Ergin S, Aydogan C, Ozturk N, Turhan E. Effects of ascorbic acid application in strawberry plants during heat stress. Turk J Agric Nat Sci. 2014;2:1486-91.

18. Ahmad I, Basra SMA, Wahid A. Exogeneous application of ascorbic acid, salicylic acid, hydrogen peroxide improves the productivity of hybrid maize at low temperature stress. Int J Agric Biol. 2014;16:825-30.

19. Alami-Milani M, Aghaei GP. Effect of ascorbic acid application on yield and yield components of lentil (Lens culinaris Medik.) under salinity stress. Int J Biosci. 2015;6:43-9.

20. Fatemi SN. Ascorbic acid it's effects on alleviation of salt stress in sunflower. Annu Res Rev Biol. 2014;4:3656-65.

21. Yao M, Ge W, Zhou Q, Zhou X, Luo M, Zhao Y, et al. Exogenous glutathione alleviates chilling injury in postharvest bell pepper by modulating the ascorbate-glutathione (AsA-GSH) cycle. Food Chem. 2021;352:129458

22. Chao YY, Hong $\mathrm{CY}$, Kao $\mathrm{CH}$. The decline in ascorbic acid content is associated with cadmium toxicity of rice seedlings. Plant Physiol Bioch. 2010;48(5):374-81.

23. Nakamura SI, Suzui N, Yin YG, Ishii S, Fujimaki S, Kawachi N, et al. Effects of enhancing endogenous and exogenous glutathione in roots on cadmium movement in Arabidopsis thaliana. Plant Sci. 2020;290:110304.

24. Semida WM, Hemida KA, Rady MM. Sequenced ascorbate-prolineglutathione seed treatment elevates cadmium tolerance in cucumber transplants. Ecotox Environ Safe. 2018;154:171-9.

25. Shigeoka S, Ishikawa T, Tamoi M, Miyagawa Y, Takeda T, Yabuta Y, et al. Regulation and function of ascorbate peroxidase isoenzymes. J Exp Bot. 2002;53(372):1305-19.

26. Rizwan M, Ali S, Hussain A, Ali Q, Shakoor MB, Zia-Ur-Rehman M, et al. Effect of zinc-lysine on growth, yield and cadmium uptake in wheat (Triticum aestivum L.) and health risk assessment. Chemosphere. 2017;187:35-42.

27. Rehman MZU, Zafar M, Waris AA, Rizwan M, Ali S, Sabir M, et al. Residual effects of frequently available organic amendments on cadmium bioavailability and accumulation in wheat. Chemosphere. 2020;244:125548.

28. Chunhabundit R. Cadmium exposure and potential health risk from foods in contaminated area, Thailand. Tox Res. 2016;32(1):65-72.
29. Lopez-Luna J, Silva-Silva MJ, Martinez-Vargas S, Mijangos-Ricardez OF, Gonzalez-Chavez MC, Solis-Dominguez FA, et al. Magnetite nanoparticle (NP) uptake by wheat plants and its effect on cadmium and chromium toxicological behavior. Sci Total Environ. 2016;565:941-50.

30. Ci DW, Jiang D, Dai TB, Jing Q, Cao WX. Effects of cadmium on plant growth and physiological traits in contrast wheat recombinant inbred lines differing in cadmium tolerance. Chemosphere. 2009;77(11):1620-5.

31. Rizwan M, Meunier JD, Davidian JC, Pokrovsky OS, Bovet N, Keller C. Silicon alleviates $\mathrm{cd}$ stress of wheat seedlings (Triticum turgidum L. cv. Claudio) grown in hydroponics. Environ Sci Pollut Res Int. 2016;23(2):1414-27.

32. Khan NA, Singh SS, Nazar R. Activities of antioxidative enzymes, Sulphur assimilation, photosynthetic activity and growth of wheat (Triticum aestivum) cultivars differing in yield potential under cadmium stress. J Agron Crop Sci. 2007;193(6):435-44.

33. Huang L, Li WC, Tam NFY, Ye ZH. Effects of root morphology and anatomy on cadmium uptake and translocation in rice (Oryza sativa L.). J Environ Sci. 2019;75:296-306.

34. Van Breusegem F, Bailey-Serres J, Mittler R. Unraveling the tapestry of networks involving reactive oxygen species in plants. Plant Physiol. 2008; 147(3):978-84.

35. Torres MA, Dangl JL. Functions of the respiratory burst oxidase in biotic interactions, abiotic stress and development. Curr Opin Plant Biol. 2005;8(4):397-403.

36. Lightfoot DJ, Boettcher A, Little A, Shirley N, Able AJ. Identification and characterisation of barley (Hordeum vulgare) respiratory burst oxidase homologue family members. Funct Plant Biol. 2008;35(5):347-59.

37. Yu SZ, Kakar KU, Yang ZX, Nawaz ZQ, Lin SF, Guo YS, et al. Systematic study of the stress-responsive Rboh gene family in Nicotiana tabacum: genomewide identification, evolution and role in disease resistance. Genomics. 2020;112(2):1404-18.

38. Gupta DK, Pena LB, Romero-Puertas MC, Hernandez A, Inouhe M, Sandalio LM. NADPH oxidases differentially regulate ROS metabolism and nutrient uptake under cadmium toxicity. Plant Cell Environ. 2017:40(4):509-26.

39. Karuppanapandian T, Moon JC, Kim C, Manoharan K, Kim W. Reactive oxygen species in plants: their generation, signal transduction, and scavenging mechanisms. Aust J Crop Sci. 2011;5(6):709-25.

40. Romero-Puertas MC, Rodrguez-Serrano M, Corpas FJ, Gomez MD, Del Rio LA, Sandalio LM. Cadmium-induced subcellular accumulation of $\mathrm{O}_{2}{ }^{-}$and $\mathrm{H}_{2} \mathrm{O}_{2}$ in pea leaves. Plant Cell Environ. 2004;27:1122-34.

41. Smeets K, Opdenakker K, Remans T, Van Sanden S, Van Belleghem F, Semane B, et al. Oxidative stress-related responses at transcriptional and enzymatic levels after exposure to $\mathrm{Cd}$ or $\mathrm{Cu}$ in a multipollution context. J Plant Physiol. 2009;166(18):1982-92.

42. Hawamda AIM, Zahoor A, Abbas A, Ali MA, Bohlmann H. The Arabidopsis RboHB encoded by At1 109090 is important for resistance against nematodes. Int J Mol Sci. 2020;21:5556.

43. Montiel J, Arthikala MK, Quinto C. Phaseolus vulgaris RbohB functions in lateral root development. Plant Signal Behav. 2013;8(1):e22694.

44. Tabaldi LA, Cargnelutti D, Goncalves JF, Pereira LB, Castro GY, Maldaner $J$, et al. Oxidative stress is an early symptom triggered by aluminum in Al-sensitive potato plantlets. Chemosphere. 2009;76(10):1402-9.

45. Valko M, Morris H, Cronin MTD. Metals, toxicity and oxidative stress. Curr Med Chem. 2005;12(10):1161-208.

46. Boscolo PRS, Menossi M, Jorge RA. Aluminum-induced oxidative stress in maize. Phytochemistry. 2003;62(2):181-9.

47. Tamas L, Dudikova J, Durcekova K, Huttova J, Mistrik I, Zelinova V. The impact of heavy metals on the activity of some enzymes along the barley root. Environ Exp Bot. 2008;62(1):86-91.

48. Liu W, Xu F, Lv T, Zhou W, Chen Y, Jin C, et al. Spatial responses of antioxidative system to aluminum stress in roots of wheat (Triticum aestivum L.) plants. Sci Total Environ. 2018;627:462-9.

49. Davletova S, Rizhsky L, Liang H, Shengqiang Z, Oliver DJ, Coutu J, et al. Cytosolic ascorbate peroxidase 1 is a central component of the reactive oxygen gene network of Arabidopsis. Plant Cell. 2005;17(1):268-81.

50. Zhang DJ, Li CX. Genotypic differences and glutathione metabolism response in wheat exposed to copper. Environ Exp Bot. 2019;157:250-9. 
51. Zafar SA, Zaidi SS, Gaba Y, Singla PSL, Dhankher OP, Li X, et al. Engineering abiotic stress tolerance via CRISPR/ Cas-mediated genome editing. J Exp Bot. 2020;71(2):470-9.

52. Kka N, Rookes J, Cahill D. The influence of ascorbic acid on root growth and the root apical meristem in Arabidopsis thaliana. Plant Physiol Bioch. 2018;129:323-30.

53. Sánchez-Fernández R, Fricker M, Corben LB, White NS, Sheard N, Leaver CJ, et al. Cell proliferation and hair tip growth in the Arabidopsis root are under mechanistically different forms of redox control. Proc Natl Acad Sci USA. 1997;94(6):2745-50.

54. Park SI, Kim JJ, Kim HS, Kim YS, Yoon HS. Enhanced glutathione content improves lateral root development and grain yield in rice plants. Plant Mol Biol. 2021;105(4-5):365-83.

55. Jung $\mathrm{H}$, Kong MS, Ch Ae MJ, Lee EJ, Jung GB, Kim YH. Effect of ascorbate on the arsenic uptake, ROS-scavenging capacity, and antioxidant homeostasis in rice. Korean J Soil Sci Fert. 2018;51:90-100.

56. Jung HI, Kong MS, Lee BR, Kim TH, Chae MJ, Lee EJ, et al. Exogenous glutathione increases arsenic translocation into shoots and alleviates arsenic-induced oxidative stress by sustaining ascorbate-glutathione homeostasis in rice seedlings. Front Plant Sci. 2019:10:1089.

57. Alamri S, Kushwaha BK, Singh VP, Siddiqui MH, Al-Amri AA, Alsubaie QD, et al. Ascorbate and glutathione independently alleviate arsenate toxicity in brinjal but both require endogenous nitric oxide. Physiol Plant. 2021:173(1):276-86.

58. Maksimovic I, Kastori R, Krstic L, Lukovic J. Steady presence of cadmium and nickel affects root anatomy, accumulation and distribution of essential ions in maize seedlings. Biol Plantarum. 2007;51(3):589-92.

59. Seregin IV, Shpigun LK, Ivanov VB. Distribution and toxic effects of cadmium and lead on maize roots. Russ J Plant Physl. 2004;51(4):525-33.

60. Jung HI, Lee BR, Chae MJ, Lee EJ, Lee TG, Jung GB, et al. Ascorbate-mediated modulation of cadmium stress responses: reactive oxygen species and redox status in Brassica napus. Front Plant Sci. 2020;11:586547.
61. Kumar S, Trivedi PK. Glutathione S-transferases: role in combating abiotic stresses including arsenic detoxification in plants. Front Plant Sci. 2018;9:751.

62. Zhang KP, Wang GY, Bao MC, Wang LC, Xie XY. Exogenous application of ascorbic acid mitigates cadmium toxicity and uptake in maize (Zea mays L.). Environ Sci Pollut R. 2019;26(19):19261-71.

63. Arnon DI, Hoagland DR. A comparison of water culture and soil as media for crop production. Science. 1939;89(2318):512-4.

64. Heath RL, Packer L. Photoperoxidation in isolated chloroplasts. I. Kinetics and stoichiometry of fatty acid peroxidation. Arch Biochem Biophys. 1968;125(1):189-98.

65. Zafar SA, Hameed A, Ashraf M, Khan AS, Qamar ZU, Li X, et al. Agronomic, physiological and molecular characterisation of rice mutants revealed the key role of reactive oxygen species and catalase in high-temperature stress tolerance. Funct Plant Biol. 2020;47(5):440-53.

66. Giannopolitis CN, Ries SK. Superoxide dismutases: I. Occurrence in higher plants. Plant Physiol. 1977;59(2):309-14.

67. Zafar SA, Uzair M, Khan MR, Patil SB, Fang JJ, Zhao JF, et al. DPS1 regulates cuticle development and leaf senescence in rice. Food Energy Secur. 2020;10:273.

68. Nicoloso FT, Tabaldi LA, Cargnelutti D, Goncalves JF, Schetinger M. Lipid peroxidation is an early symptom triggered by aluminum, but not the primary cause of elongation inhibition in pea roots. Chemosphere. 2009;76:1402-9.

69. Zhou T, Yue CP, Liu Y, Zhang TY, Huang JY, Hua YP. Multiomics reveals pivotal roles of sodium translocation and compartmentation in regulating salinity resistance in allotetraploid rapeseed. J Exp Bot. 2021;72:5687-708.

\section{Publisher's Note}

Springer Nature remains neutral with regard to jurisdictional claims in published maps and institutional affiliations.
Ready to submit your research? Choose BMC and benefit from:

- fast, convenient online submission

- thorough peer review by experienced researchers in your field

- rapid publication on acceptance

- support for research data, including large and complex data types

- gold Open Access which fosters wider collaboration and increased citations

- maximum visibility for your research: over $100 \mathrm{M}$ website views per year

At BMC, research is always in progress.

Learn more biomedcentral.com/submissions 